TAO, Vol. 16, No. 2, 345-360, June 2005

\title{
The Distribution Characteristics of Elemental Components between Fine and Coarse Particle Fractions in Chongju, Korea
}

\author{
Hak Sung Lee ${ }^{1}$, Byung-Wook Kang ${ }^{2}$ and Ki-Hyun Kim ${ }^{3, *}$
}

(Manuscript received 24 April 2004, in final form 17 February 2005)

\begin{abstract}
The distribution characteristics of airborne particulate matter (PM) were investigated in terms of the relationships between different constituents (elements) and between different particle ranges (fine vs. coarse) from the city of Chongju, South Korea for approximately a year (October 1995 to August 1996). For the purpose of our study, the elemental compositions of both fine (FP: PM $_{2.5}$ ) and coarse particle (CP: $\left.\mathbf{P M}_{2.5-10}\right)$ fractions were determined by proton induced $x$-ray emission (PIXE). Based on our study, the annual mean concentrations of PM in FP and $\mathrm{CP}$ fractions were found to be 41.4 and $29.6 \mu \mathrm{m}^{-3}$, respectively. The major elemental components of $\mathrm{CP}$ were found to be in the order of $\mathrm{Si}, \mathrm{Ca}, \mathrm{Al}, \mathrm{Fe}, \mathrm{K}$, and $\mathrm{Cl}$, while those of $\mathrm{FP}$ were $\mathrm{S}, \mathrm{Cl}, \mathrm{Si}, \mathrm{K}$, and $\mathrm{Fe}$. If the temporal patterns of $\mathrm{PM}$ were compared across seasons, the most prominent pattern was found to be a relative depletion in coarse-mode concentrations during the summer's possibly due to efficient wet scavenging. On the other hand, the summing term for all elements showed consistently a summertime depletion pattern for all particle fractions. Our analysis of the relative relationships between PM and elements confirmed that the contribution of elemental components to PM mass concentrations can differ significantly across different particle size ranges and seasons.
\end{abstract}

(Key words: Fine ( $\left.\mathrm{PM}_{2.5}\right)$ and coarse ( $\left.\mathrm{PM}_{2.5-10}\right)$ particles, Dichotomous sampler, Proton induced $\mathrm{x}$-ray emission (PIXE), Ionic composition, Chongju)

\footnotetext{
${ }^{1}$ Department of Environmental, Civil and Information System, Seowon University, Korea

2 Department of Environmental Industry, Chongju National College of Science and Technology, Korea

${ }^{3}$ Department of Earth \& Environmental Sciences, Sejong University, Seoul, Korea

* Corresponding author address: Prof. Ki-Hyun Kim, Department of Earth \& Environmental Sciences, Sejong University, Seoul, Korea; E-mail: khkim@sejong.ac.kr
} 


\section{INTRODUCTION}

By operational definition, particles less than $2.5 \mu \mathrm{m}$ in diameter belong to the fine particle (FP) fraction, whereas those greater than $2.5 \mu \mathrm{m}$ are of the coarse particle (CP) fraction (e.g., Seinfeld 1986). Like physical differences in particle size, sources of each particle fraction have been distinguished from each other in various respects. The formation of fine particles occurs primarily as the result of various man-made activities (including the combustion of fossil fuels or secondary chemical reactions in the atmosphere). In fact, a number of previous studies have demonstrated that toxic metallic species (such as arsenic, selenium, cadmium, and zinc) are more concentrated in the fine, rather than coarse, particle fraction (e.g., Kim et al. 2003). By contrast, coarse particles are produced primarily by such processes as wind erosion, primary emissions, sea spray, and mechanical processes (Pakkanen et al. 2001a, b). Hence, the coarse particle mode of PM is known to consist mainly of crustal components such as iron, calcium, and silicon (Mishra et al. 2004).

A better knowledge of the size distributions of the ambient aerosols can provide valuable clues in predicting the pathways leading to their formation and transformation in the atmosphere (Gramotnev and Ristovski 2004; Hazi et al. 2003). Moreover, because of the great differences in origin and associated physicochemical properties between different particle size ranges, diverse statistical treatment is also allowable for the apportionment of sources (e.g., Polisar et al. 2001) and/or for the evaluation of health risks (e.g., Lall et al. 2004). A prerequisite for the application of such sophisticated tools is detailed information concerning the chemical composition of particles. This means the acquisition of a quantitative data set is fundamental to the establishment of strategies to control urban aerosol pollution problems.

Although numerous studies have been performed to investigate the atmospheric chemistry of PM, information concerning the behavior and fate of PM is still insufficient in certain respects; for example, changes in chemical composition across different particle size ranges (e.g., Yao et al. 2003). In this study, in order to investigate the factors and processes controlling the distribution of airborne PM, measurements were undertaken to simultaneously analyze PM samples in both fine and coarse mode in the city of Chongju, a moderately urbanized area in Korea. Through a thorough investigation of both absolute and relative relationships between different elements, we attempted to elucidate the main mechanisms that contribute to the formation of PM in Chongju, Korea. In addition, based on these measurement data, we discuss the fundamental factors that underlie the temporal distribution of airborne PM.

\section{METHODS}

In this study, both fine and coarse particle samples were collected and analyzed simultaneously for the period, October 1995 through August 1996 from a total of 58 individual experiments. The sampling site location was on the roof of the Chongju National College of Science and Technology building (15 m above ground level), which is located in a commercial-residential complex in central Chongju City. There are no large buildings around the sampling site to disrupt wind flow patterns. The site is approximately $3.8 \mathrm{~km}$ from the nearest highway, Kyung Bu line, and $56 \mathrm{~km}$ away from the west coastal area. The city represents a 
moderately urbanized area $\left(154 \mathrm{~km}^{2}\right)$, about $115 \mathrm{~km}$ from Seoul, the capital of Korea (Fig. 1). It lies within a topographic basin surrounded by mountains to the east and south and is open to the west and north. The prevailing wind at the study site is either southwesterly or northwesterly. The climate of Chongju is characterized by large variations in temperature, from a monthly mean of $-1.3^{\circ} \mathrm{C}$ in January to $26^{\circ} \mathrm{C}$ in August. Its population $(570,000)$ is growing rapidly, and at present the number of vehicles on the road $(145,000)$ is approximately five times that of 1990. It has been shown that the major emission sources of the city are industry, domestic heating, and vehicles with the main fuel sources in industry and heating being heavy and light oils (Chongju 1996). Major industries include electronics, metal assemblies, textiles, food, etc. These industrial sources are approximately $1.5 \mathrm{~km}$ from the monitoring site located northwest of downtown Chongju. The city experiences air pollution problems due to the combined effects of the topography, meteorological conditions, increasing fuel usage by industry, vehicles and continuous growth in population.

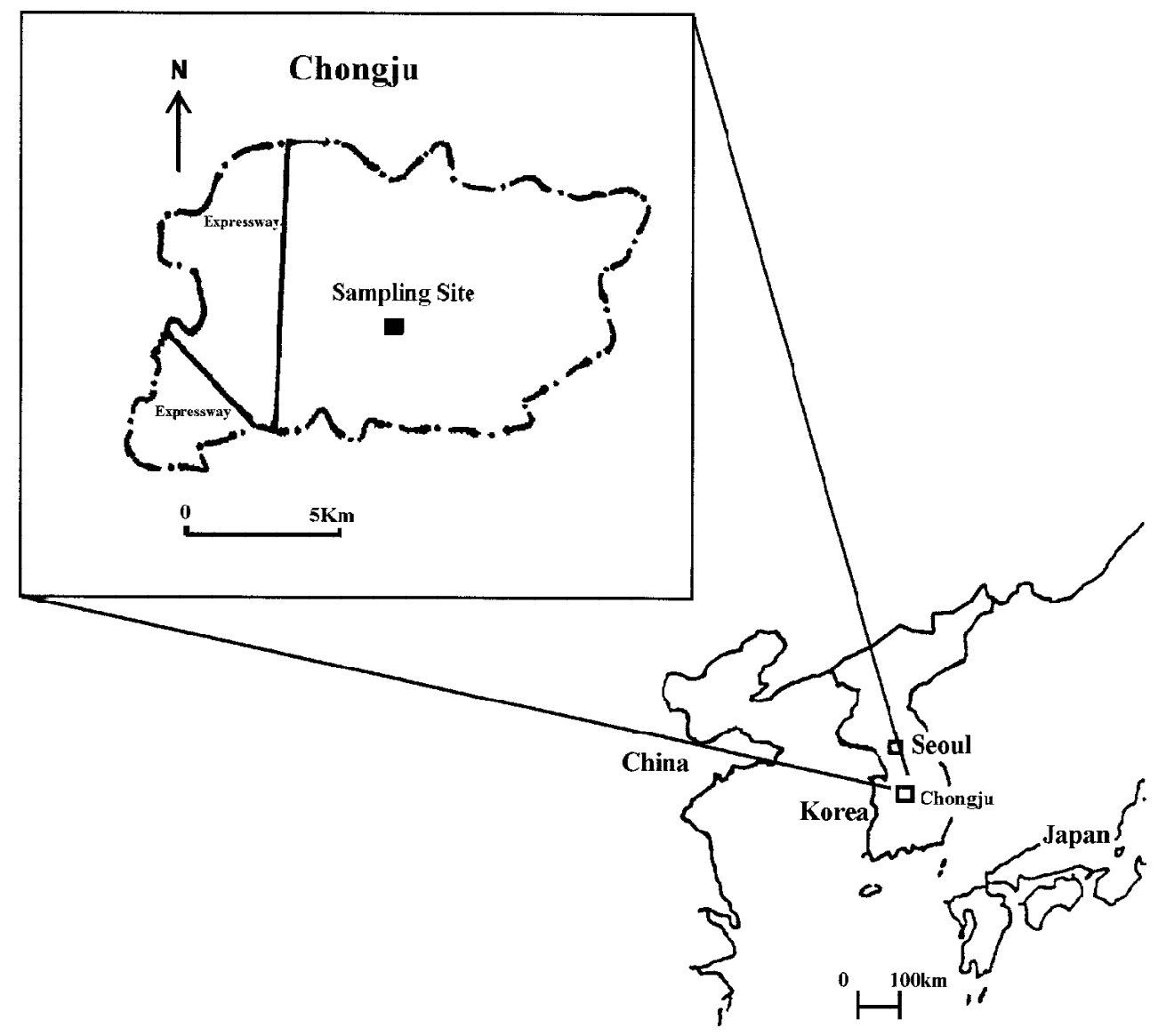

Fig. 1. A geographical location of the study site, Chongju in Korea. 
The Korean Peninsula during the spring months comes under the influence of Asian dust storms, which contain high concentrations of earthen components originating from regions in northern China and/or the Mongolia plateau. Chung and Yoon (1996) found that the chief layer of a dust cloud moved to the east and southeast by a steering airflow at $850-500 \mathrm{hPa}$; and they estimated atmospheric loadings for this cloud to be 1.5 Mton.

The collection of PM samples was performed routinely from 8 a.m. in the morning at $24 \mathrm{~h}$ intervals using a dichotomous sampler (Model SA241, Andersen Co.). Instead of covering every month throughout the year, we conducted continuous sampling over intervals of 3 to 4 days for two representative months in each season. The particles entering the dichotomous sampler with an aerodynamic diameter below $10\left(\mathrm{PM}_{10}\right)$ were divided into two size fractions by means of a virtual impactor with a 2.5 cutoff point. These two particle fractions are referred to as fine (FP: $\mathrm{d}_{\mathrm{a}}<2.5 \mu \mathrm{m}$ ) and coarse particle fractions (CP: $2.5 \mu \mathrm{m}<\mathrm{d}_{\mathrm{a}}<10 \mu \mathrm{m}$ ), respectively. The sampler was operated at a total flow rate of 16.7 liters $\mathrm{min}^{-1}$ (the flow rates of coarse and fine fractions were 1.67 and $15 \mathrm{lmin}^{-1}$, respectively). Particles were collected on $37 \mathrm{~mm}$ Teflon membrane filters ( $1 \mu \mathrm{m}$ pore size) and supported by rubber o-rings (Gelman Sciences). The $\mathrm{PM}_{2.5}$ mass was determined gravimetrically using a microbalance (Cahn $\mathrm{C}-35$ ), which is sensitive to changes as small as $0.1 \mu \mathrm{g}$. All Teflon filters were pre- and postweighed (below $35^{\circ} \mathrm{C}$ and $50 \%$ relative humidity), and the net weights were corrected with three unsampled control filters. All Teflon filters were conditioned before and after sampling in a clean chamber (Nikko auto dry desiccator) for at least $24 \mathrm{hrs}$.

Elemental composition was analyzed using a proton induced $\mathrm{x}$-ray emission (PIXE) by the Element Analysis Corporation (Lexington, KY, USA); this instrument has the capacity to analyze up to 72 elements (sodium to uranium). Three blank filters were analyzed and used to correct the mass of each element contained in the sample filters. Information regarding the detection limit (DL) values for the series of elements measured is shown in Table 1, which includes sodium $(\mathrm{Na})$, magnesium $(\mathrm{Mg})$, aluminum $(\mathrm{Al})$, silicon $(\mathrm{Si})$, sulfur $(\mathrm{S})$, chlorine $(\mathrm{Cl})$, potassium $(\mathrm{K})$, calcium $(\mathrm{Ca})$, titanium $(\mathrm{Ti})$, manganese $(\mathrm{Mn})$, iron $(\mathrm{Fe})$, copper $(\mathrm{Cu})$, zinc $(\mathrm{Zn})$, and lead $(\mathrm{Pb})$. These values were calculated on the basis of analyzer sensitivity using 24hr samples collected separately at coarse $\left(1.67 \mathrm{lmin}^{-1}\right)$ and fine-mode flow rates $\left(15 \mathrm{lmin}^{-1}\right)$. The accuracy of the measurements of these species was typically within $10 \%$ of the standard value. The precision was typically computed between 1 to $10 \%$ on the basis of replicate analysis of air samples.

\section{RESULTS AND DISCUSSIONS}

\subsection{The Overall Pattern of PM Experimental Results}

In Table 2, a statistical summary of our compositional analyses of both $\mathrm{FP}\left(\mathrm{d}_{\mathrm{a}}<2.5 \mu \mathrm{m}\right)$ and CP mode $\left(2.5 \mu \mathrm{m}<\mathrm{d}_{\mathrm{a}}<10 \mu \mathrm{m}\right)$ samples is presented using some major parameters derived from our measurement data. (Data for the $\mathrm{PM}_{10}$ fraction represent the sum of both FP and CP fractions, as they were collected separately by the dichotomous sampler.) To make a meaningful comparison of the relative roles for the two particle fractions between the different 
elemental components, a comparison of the results was made using the following terms: (1) two absolute values: $\mathrm{PM}\left(\mu \mathrm{g} \mathrm{m}^{-3}\right)$ and $\Sigma$ (element) $\left(\mathrm{ng} \mathrm{m}^{-3}\right)$; and (2) two relative values derived as concentration ratios: $\Sigma$ (element)/PM (\%) and F/C ratio (unitless). Here, the summing term for element $[\Sigma($ element $)]$ was derived by summing up the individual concentrations of all elements investigated in this study (Fig. 2).

Table 1. Detection limit (DL) values of elements for the analysis of the fine and coarse particles $\left(\mathrm{ng} \mathrm{m}^{-3}\right)$ in this study.

\begin{tabular}{|c|c|c|}
\hline Species & $\mathbf{P M}_{2.5}$ & $\mathbf{P} \mathbf{M}_{2.5-10}$ \\
\hline $\mathrm{Na}$ & 25.5 & 20.3 \\
\hline $\mathbf{M g}$ & 14.1 & 11.3 \\
\hline Al & 11.7 & 9.30 \\
\hline Si & 11.0 & 8.70 \\
\hline $\mathbf{S}$ & 10.3 & 8.30 \\
\hline $\mathrm{Cl}$ & 10.3 & 8.20 \\
\hline $\mathbf{K}$ & 9.60 & 7.60 \\
\hline $\mathrm{Ca}$ & 14.7 & 11.7 \\
\hline $\mathbf{T i}$ & 6.90 & 5.50 \\
\hline V & 5.10 & 4.10 \\
\hline $\mathrm{Cr}$ & 2.60 & 2.00 \\
\hline Mn & 2.10 & 1.70 \\
\hline $\mathrm{Fe}$ & 3.40 & 2.70 \\
\hline $\mathbf{N i}$ & 4.40 & 3.60 \\
\hline $\mathrm{Cu}$ & 2.40 & 1.90 \\
\hline $\mathrm{Zn}$ & 2.10 & 1.70 \\
\hline $\mathbf{B r}$ & 4.50 & 3.60 \\
\hline $\mathbf{P b}$ & 10.8 & 8.70 \\
\hline
\end{tabular}




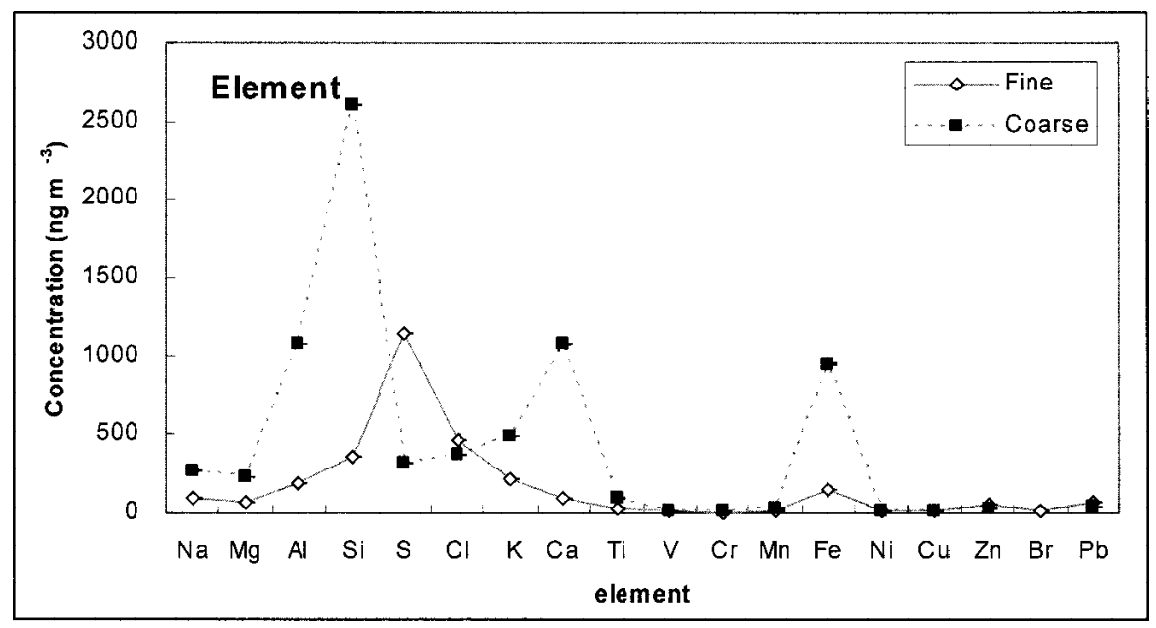

Fig. 2. Comparison of the mean concentrations of elemental components between fine $\left(\mathrm{PM}_{2.5}\right)$ and coarse $\left(\mathrm{PM}_{2.5-10}\right)$ particle fractions.

The results shown in Table 2 indicate several interesting aspects of PM geochemistry. First of all, the mean PM concentrations are larger in FP $\left(41.4 \mu \mathrm{g} \mathrm{m}^{-3}\right)$ than in CP $\left(29.5 \mu \mathrm{g} \mathrm{m}^{-3}\right)$. This is compatible with results from many previous studies conducted in diverse urban areas in that $\mathrm{PM}_{2.5}$ mass can account for $27 \sim 80 \%$ of $\mathrm{PM}_{10}$ mass (Zhuang et al. 1999, Alonso et al. 1997, Chan et al. 1997, Harrison et al. 1997, Chow et al. 1996). On the other hand, the pattern for elemental mean concentration data is completely reversed with the values for FP and CP fractions at 2.76 and $7.54 \mu \mathrm{g} \mathrm{m}^{-3}$, respectively. Our results thus indicate the absolute dominance of elemental components in the CP mode. To analyze the diverse features of PM chemistry, all the different individual constituents used for the derivation of the summation term in Table 2 are analyzed independently in Table 3 . For the computation of each statistical term shown in the tables, we excluded concentration values below detection limits (BDL) to place limitations on uncertainties in such lower-bound concentration ranges. However, to describe the occurrence patterns of such lower-bound concentration values, the frequency of all BDL occurrences are given additionally in tables with respect to all and seasonally divided data sets. Per our classification of data in terms of detectibility, the acquisition patterns of valid data sets appear to contrast quite sharply between various data groups. For example in the case of many elements (e.g., $\mathrm{Na}, \mathrm{Mg}, \mathrm{Cl}, \mathrm{Ti}, \mathrm{Cr}, \mathrm{Mn}, \mathrm{Ni}$, and $\mathrm{Cu}$ ), the occurrences of BDL readings occurred primarily in the FP fraction. By contrast, the opposing patterns were also evident for a few elements (including $\mathrm{V}, \mathrm{Ni}$, and $\mathrm{Pb}$ ), such that their BDLs were found predominantly in the $\mathrm{CP}$, rather than FP, fraction. Moreover, if these elemental data are compared on a seasonal basis, BDL values were observed most commonly during summer, probably due to enhanced washout of these constituents with the aid of heavy or frequent precipitation. Specially, the major unidentified elements (manganese and titanium) that are wet scavenged in the summer (Table 3). 
Lee et al.

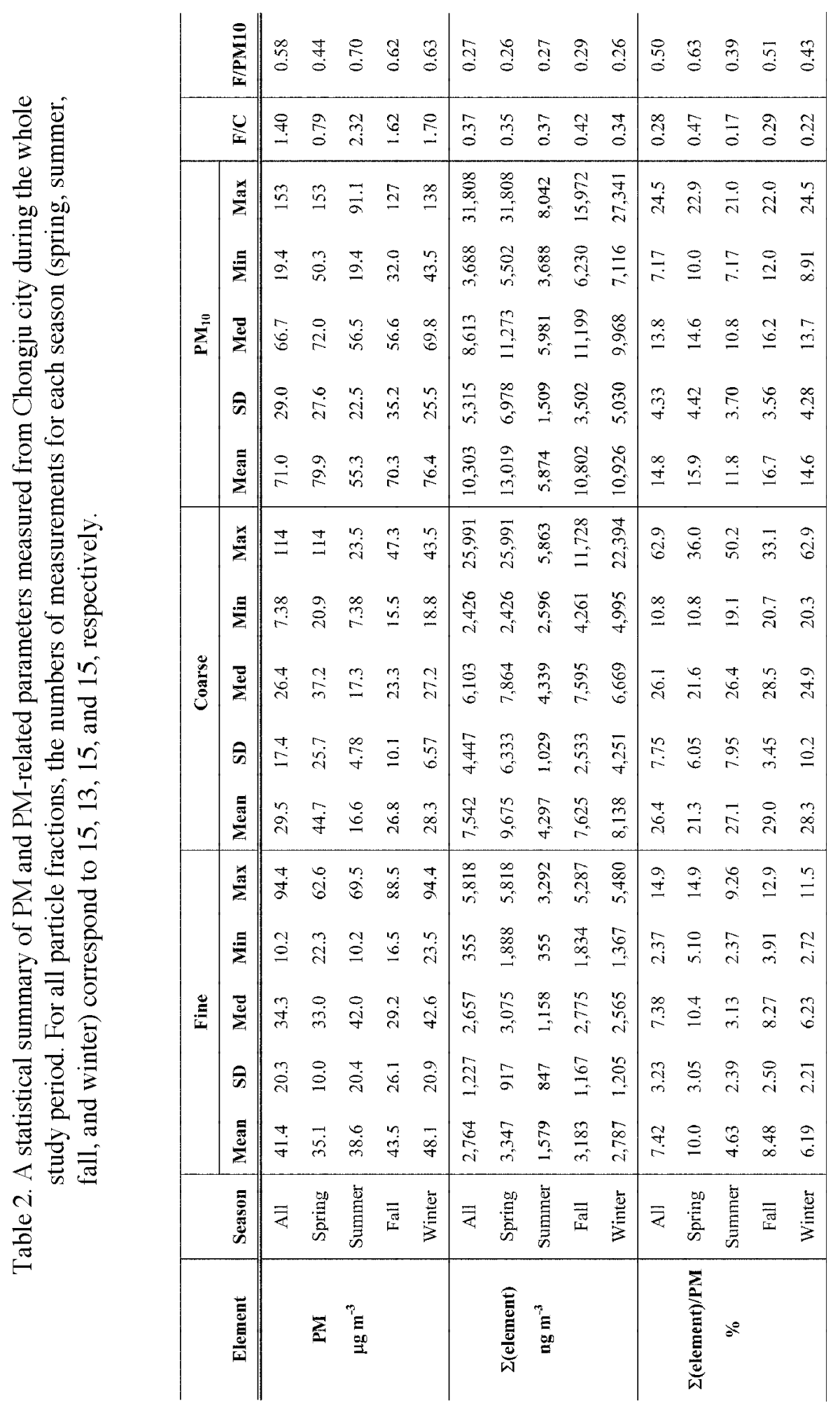




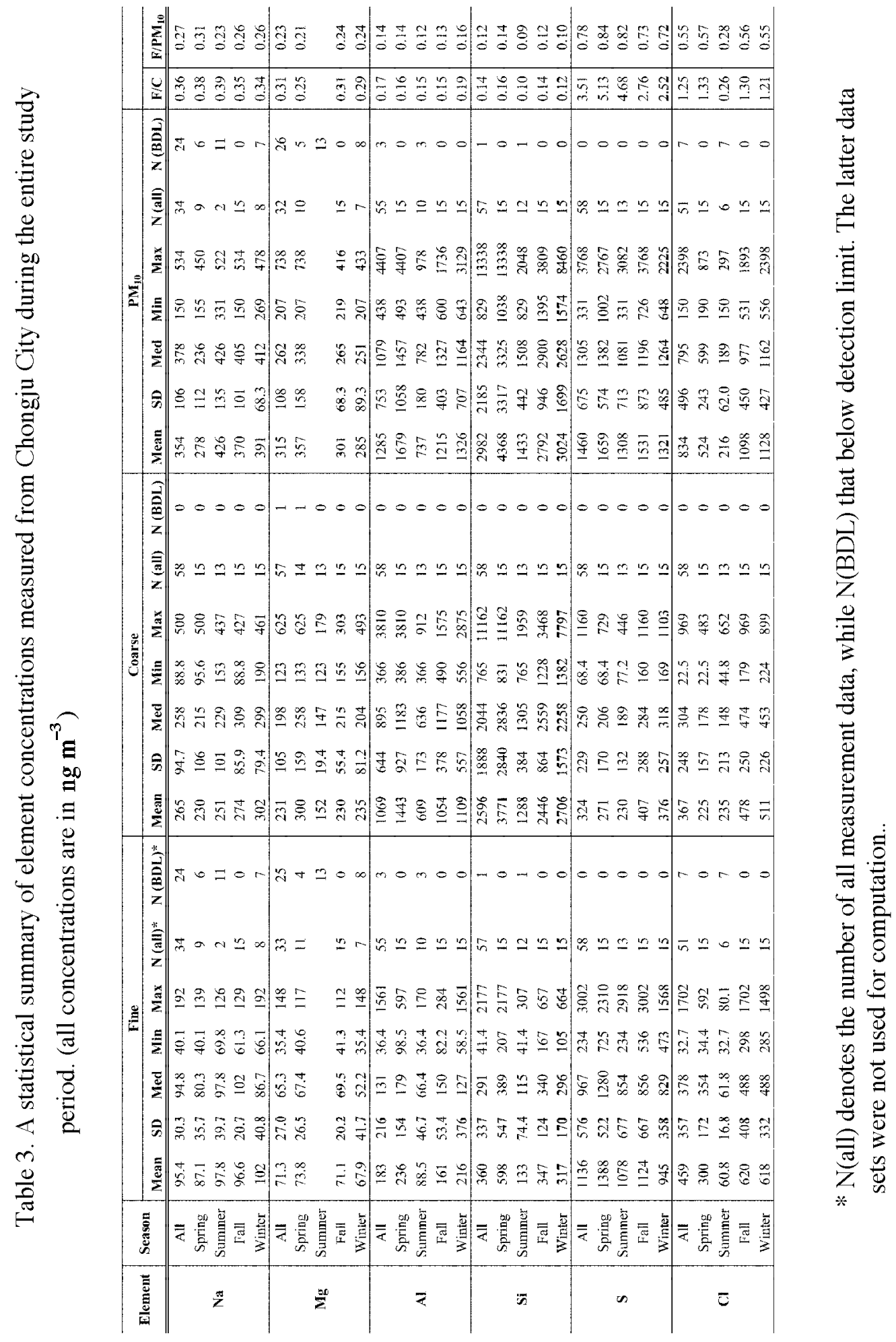




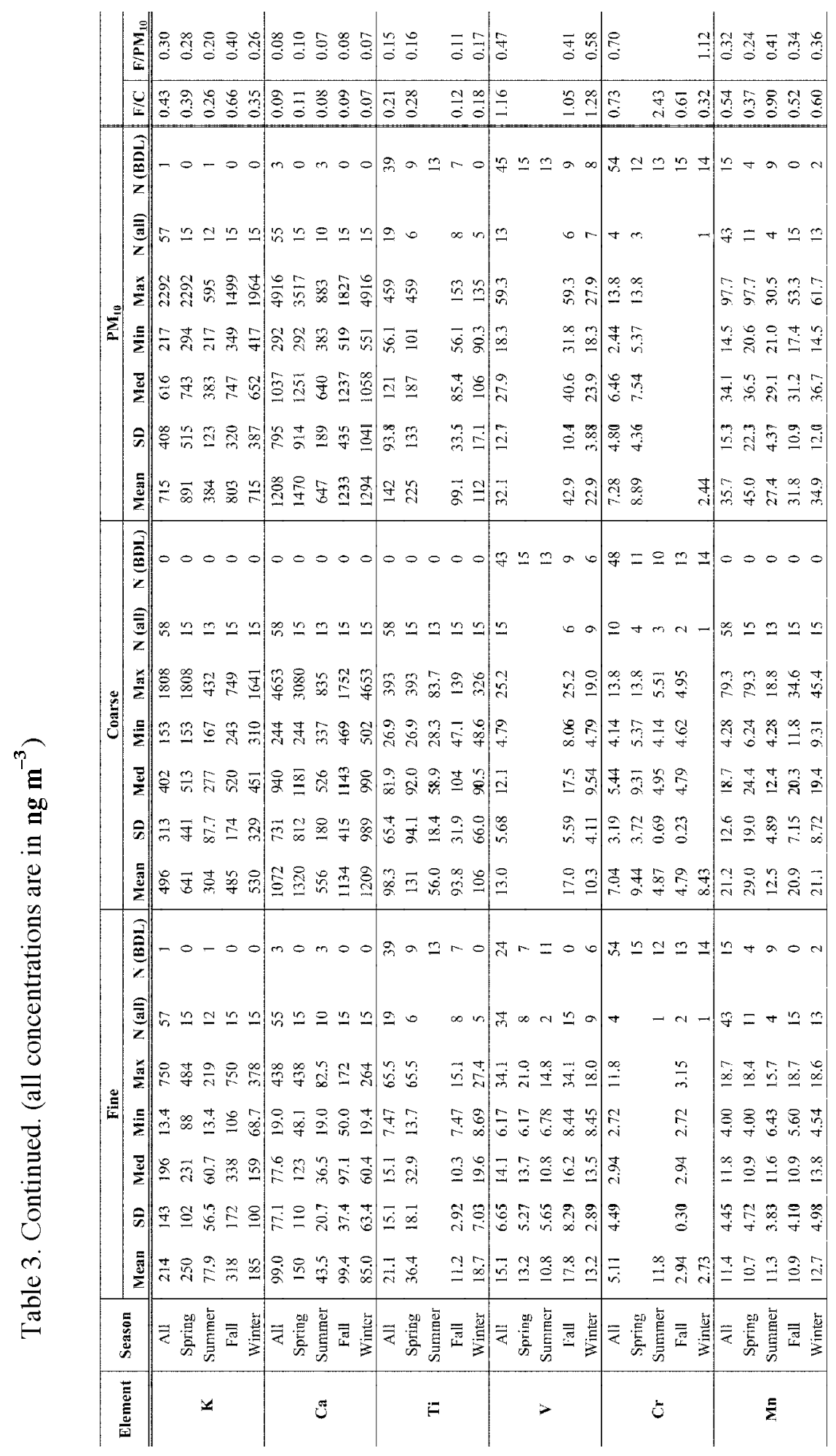




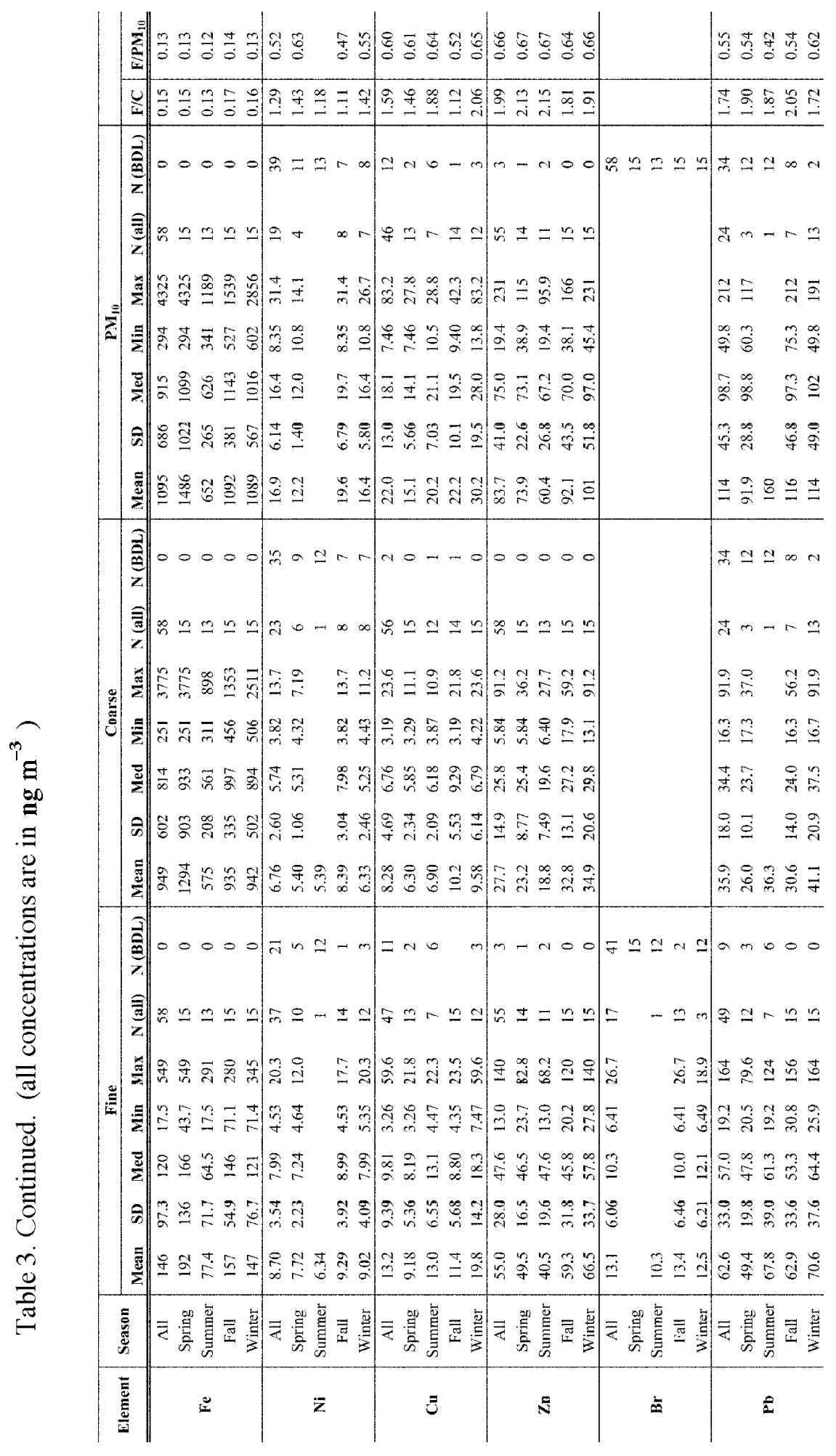




\subsection{The Distribution Characteristics of Elemental Components in the Study Area}

In order to examine both absolute and relative contributions of elemental components contributing to PM composition, their magnitude was compared between the two particle fractions. According to our comparison based on the summarized results in Table 2, both similarities and dissimilarities coexist in their distribution patterns across particle sizes. In general, the elemental concentrations in the $\mathrm{CP}$ fraction appear to be significantly higher than their FP counterpart. In the $\mathrm{CP}$ fraction, their mean concentrations, expressed in $\mathrm{ng} \mathrm{m}^{-3}$, were found to decrease in the following order: $\mathrm{Si}$ (2596), $\mathrm{Ca}$ (1072), $\mathrm{Al}$ (1069), $\mathrm{Fe}$ (949), K (496), $\mathrm{Cl}$ (367), S (324), Na (265), Mg (231), Ti (98), Pb (36), Zn (28), Mn (21), V (13), Cu (8.3), Cr (7.0), and $\mathrm{Ni}$ (6.8). On the other hand, if the results are compared for the FP fraction, the relative patterns for most elements are quite compatible with a few exceptions such as: $\mathrm{S}$ (1136), Cl (459), Si (360), K (214), Al (183), Fe (146), Ca (99), Na (95), Mg (71), Pb (63), Zn (55), $\mathrm{Ti}(21), \mathrm{V}(15), \mathrm{Cu}, \mathrm{Br}(13), \mathrm{Mn}$ (11), $\mathrm{Ni}$ (8.7), and $\mathrm{Cr}$ (5.1). It is also worth noting that the changes in their concentration levels, in general, contrast starkly between major crustal and trace metal components. The former tends to exhibit a significant concentration drop from the $\mathrm{CP}$ to the FP fraction ( $\mathrm{Si}, \mathrm{Ca}, \mathrm{Al}, \mathrm{Fe}, \mathrm{K}, \mathrm{Na}, \mathrm{Mg}$, and $\mathrm{Mn}$ ), while the latter tends to gain concentrations in the FP mode on many occasions $(\mathrm{Pb}, \mathrm{Zn}, \mathrm{V}, \mathrm{Cu}$, and $\mathrm{Ni})$. If examined in terms of correlation analysis, the elements with similar source types generally exhibit significant correlations with each other. However, if changes in their relative ordering are concerned, an element like $\mathrm{S}$ appears to undergo the most significant changes of all. In the FP mode, $\mathrm{S}$ becomes the most dominant component of FP, as it alone can account for almost one half of the total elemental mass in the FP fraction.

As elements like $\mathrm{Na}, \mathrm{Mg}, \mathrm{Al}, \mathrm{Si}, \mathrm{K}, \mathrm{Ca}, \mathrm{Ti}, \mathrm{Mn}$ and $\mathrm{Fe}$ are known to be of crustal origin, they tend to be notably abundant in the CP rather than FP fraction (Chan et al. 1999, Chen et al. 1997, Chow et al. 1996, Lyons et al. 1993, Seinfeld 1986). Iron and manganese, however, are crustal elements that can also be emitted by industrial sources, in particular iron and steel operations (Chow 1996, Huang et al. 1994). However, in our study area, there are no known sources of iron and steel operations. Hence these elements are suspected to be of crustal origin. As previously mentioned, elemental sulfur was found to be the predominant component of FP elemental mass. The main sulfur sources in Chongju appear to come from the heavy and light oils used in industry and heating. Road salt, sea salt spray, automobile emissions, and coal combustion can act as sources of chlorine in the atmosphere (e.g., Spengler and Thurston 1983). However, there are also contrasting reports of $\mathrm{Cl}$ fractionation. For instance, Chow et al. (1996) reported that substantial amounts of $\mathrm{Cl}$ (and $\mathrm{Na}$ ) were detected in the $\mathrm{CP}$ fraction at the coastal site. The correlation coefficients of $\mathrm{Cl}$ and $\mathrm{Na}$ in the $\mathrm{CP}$ and $\mathrm{FP}$ fractions were 0.7 and 0.3 , respectively, suggesting that these components in the FP fraction did not originate from the same sources; $\mathrm{Cl}$ in the fine particles may have originated from anthropogenic sources. Elemental $\mathrm{K}$ in aerosols can come from either crustal matter or smoke. Therefore, non-soil K, rather than total K, has been usually used to indicate smoke emissions (Chan et al. 1999, Linda et al. 1997, Chow 1996, Huang et al. 1994).

Generally reduced $\mathrm{PM}_{2.5} / \mathrm{PM}_{10}$ ratios for potassium are consistently found from many sites such as those for Chongju, Los Angeles, Brisbane, and Helsinki (Table 4). Several metals 
including $\mathrm{Pb}, \mathrm{Zn}$, and $\mathrm{Cu}$ are found to be enriched in $\mathrm{FP}$ rather than $\mathrm{CP}$ mode. These metals are generally known to be emitted from combustion processes (Chan 1999, Chow 1996, Huang et al. 1994, Spengler and Thurston 1983). Lyons et al. (1993) also reported that particle size distributions of metals like $\mathrm{Cu}$ and $\mathrm{Zn}$ can be dominated by particle size ranges of less than $1 \mu \mathrm{m}$ in diameter, indicating the possibly strong influence of anthropogenic sources. $\mathrm{Pb}$ has been considered as the traditional marker element for gasoline-powered vehicles. However, $\mathrm{Pb}$ does not appear to be an efficient marker in our study area or in S. Korea, as the use of leaded gasoline has been phased out since 1993 (e.g., Mishra et al. 2004). The comparative results summarized in Table 3 also indicate that those metals tend to be enriched in the FP fraction in most study sites including Los Angeles, Brisbane, and Helsinki (Table 4).

\subsection{Temporal variation of PM compositions between elements}

In order to more precisely understand the PM distribution characteristics in the study area, the concentrations of various elements measured in this study were further analyzed to assess factors affecting PM compositional changes across different seasons. It is worth noting that $\mathrm{PM}$ mass concentrations determined as both total $\left(\mathrm{PM}_{10}\right)$ and $\mathrm{CP}$ fraction $\left(\mathrm{PM}_{2.5-10}\right)$ complied well with general expectations, such as their relative depletions during the summer/fall period. As coarser particles can be more effectively removed by wet scavenging during the rainy summer season, they tend to exhibit more depletion during summer than their fine particle counterparts. By contrast, no such signal is apparent in fine-mode PM distribution; its distribution may be affected by different factors such as the chemistry of ionic components that are more abundant in the fine particle mode.

As seen in Fig. 3, the distribution patterns for the sum of elemental components contrast slightly with those of PM size distribution; they are consistently depleted in the summertime, regardless of particle size. However, if we compare the pattern after normalizing the elemental concentration by PM mass concentration, the coarse fraction does not exhibit any more depletion (Fig. 3, bottom). It is hence reasonable to suspect that summertime scavenging of elemental components in the coarse mode may proceed less efficiently than those of non-elemental components. When this type of seasonal pattern is examined across different elements, patterns do contrast among elements. Although most elemental components generally appear to comply well with the patterns of PM or the sum of elements, a few elements seem to exhibit their own unique patterns such as $\mathrm{Na}, \mathrm{Cu}$, and $\mathrm{Pb}$.

\section{CONCLUSIONS}

In order to elucidate the relationship between size distribution and chemical characteristics of airborne particles, we investigated elemental constituents of aerosols between two size ranges across fine and coarse particle fractions in a moderately urbanized area in Korea. The results of our investigation generally indicated that the size distribution characteristics of PM can be accounted for by the complicated roles that exist between different particle fractions. It was found that the mass concentration of the $\mathrm{CP}$ mode was affected highly effectively by elemental components. If compared in terms of the summation of elements, the combined concen- 
Table 4. The mean ratios of $\mathrm{PM}_{2.5}$ to $\mathrm{PM}_{10}\left(\mathrm{PM}_{2.5} / \mathrm{PM}_{10}\right)$. Both mass and elemental concentrations of important species are compared with other studies.

\begin{tabular}{lcccc}
\hline Species & $\begin{array}{c}\text { Chongju } \\
\text { (this study) }\end{array}$ & $\begin{array}{c}\text { Los Angeles }^{\mathbf{a}} \\
\text { U.S.A. }\end{array}$ & $\begin{array}{c}\text { Brisbane }^{\mathrm{b}} \\
\text { Australia }\end{array}$ & $\begin{array}{c}\text { Helsinki }^{\mathrm{c}} \\
\text { Finland }\end{array}$ \\
\hline $\mathbf{N a}$ & 0.17 & - & - & 0.36 \\
$\mathbf{M g}$ & 0.15 & 0.19 & - & 0.16 \\
$\mathbf{A l}$ & 0.14 & 0.14 & 0.15 & 0.1 \\
$\mathbf{S i}$ & 0.12 & 0.09 & 0.11 & - \\
$\mathbf{S}$ & 0.78 & - & 0.76 & - \\
$\mathbf{C l}$ & 0.52 & - & 0.16 & - \\
$\mathbf{K}$ & 0.3 & 0.23 & 0.42 & 0.3 \\
$\mathbf{C a}$ & 0.08 & 0.10 & 0.11 & 0.13 \\
$\mathbf{T i}$ & 0.07 & 0.09 & 0.15 & - \\
$\mathbf{M n}$ & 0.27 & 0.50 & 0.50 & 0.28 \\
$\mathbf{F e}$ & 0.13 & 0.18 & 0.20 & 0.16 \\
$\mathbf{C u}$ & 0.58 & - & - & 0.33 \\
$\mathbf{Z n}$ & 0.65 & 0.60 & 0.75 & 0.64 \\
$\mathbf{P b}$ & 0.8 & - & 0.82 & 0.74 \\
$\mathbf{M a s s}$ & 0.58 & 0.59 & 0.41 & 0.48 \\
\hline
\end{tabular}

a) January 1995 to February 1996 in downtown Los Angeles, USA (Kim et al. 2000).

b) December 1993 to November 1995 in Brisbane, a subtropical coastal city in Australia (Chan et al. 1999).

c) Aerosol samples of PM2.3 and PM2.3-15 collected from April 1996 to June 1997 in Helsinki, Finland (Pakkanen et al. 2001b).

d) Not available.

tration of $\mathrm{CP}\left[\Sigma(\text { element })_{\mathrm{c}}=7.5 \mu \mathrm{g} \mathrm{m}^{-3}\right.$ ] exceeded its counterpart $\left[\Sigma(\text { element })_{\mathrm{f}}=2.8 \mu \mathrm{g} \mathrm{m}^{-3}\right]$. The major elemental components of $\mathrm{CP}$ were found to be in the order of $\mathrm{Si}, \mathrm{Ca}, \mathrm{Al}, \mathrm{Fe}, \mathrm{K}$, and $\mathrm{Cl}$, while those of $\mathrm{FP}$ were $\mathrm{S}, \mathrm{Cl}, \mathrm{Si}, \mathrm{K}$, and $\mathrm{Fe}$.

According to our study, clear seasonal patterns were observed consistent for both the different PM modes and different constituents. First of all, the CP mass data represented as $\left(\mathrm{PM}_{2.5-10}\right)$ showed rather strong seasonal variations, which can be described as enhancement 

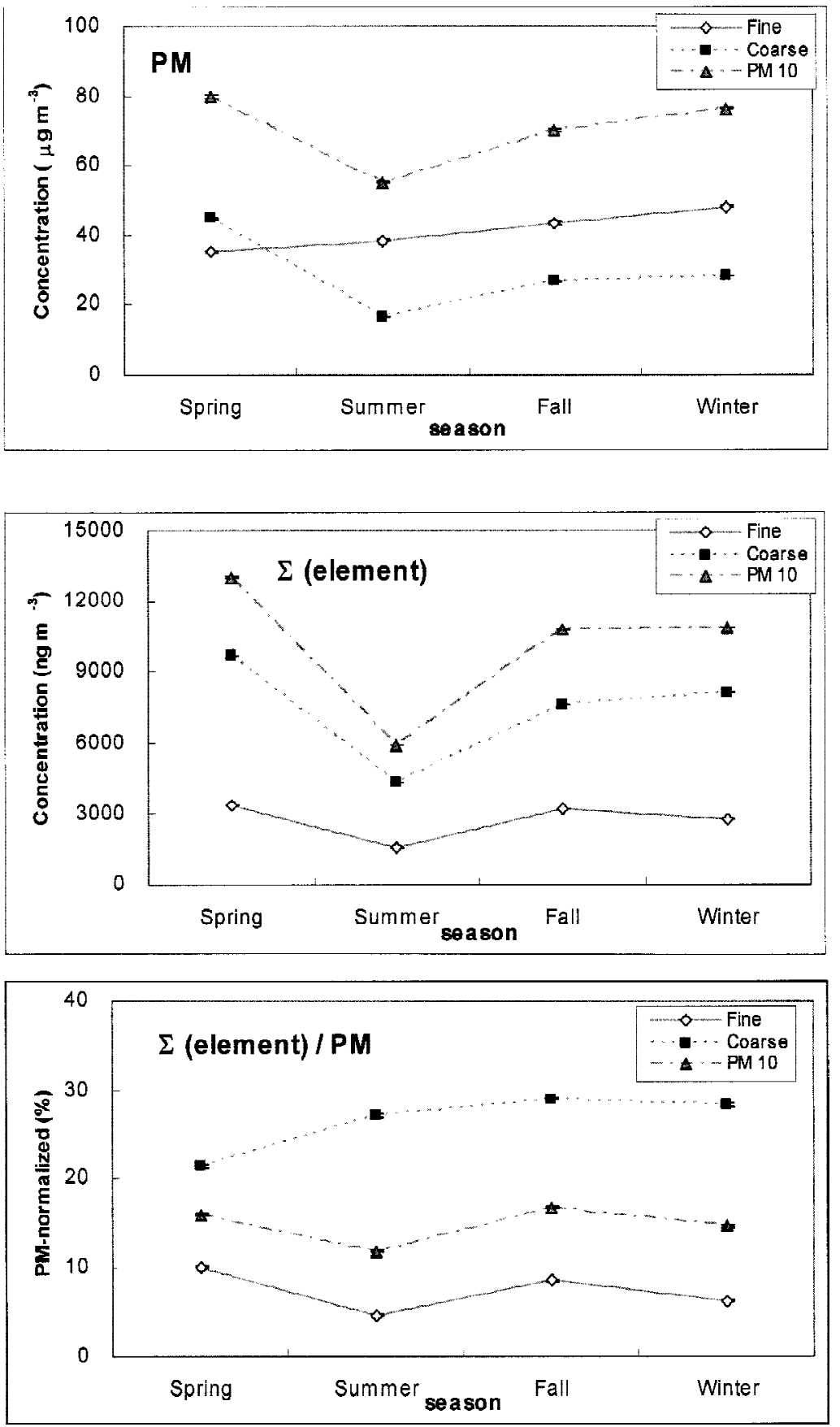

Fig. 3. Seasonal distribution patterns of PM and the associated elemental components determined from Chongju during 1995 - 1996. 
in the winter/spring seasons relative to summer/fall seasons. Here mass and abundant species generally showed higher concentrations in the spring; this may reflect to some degree the influence of soil dust from China as a result of Asian dust storms. On the other hand, the results of the FP mass data were clearly distinguished from such patterns. The FP mode, in fact, tended to show moderately enhanced concentration levels during the summer relative to the spring or fall. If the mass ratio of $\mathrm{PM}_{2.5} / \mathrm{PM}_{10}$ is evaluated, its values are also higher in summer and than in the spring.

This detailed analysis of physical and chemical properties of airborne particles has been helpful in providing valuable insights into their geochemistry in a moderately urbanized area.

Acknowledgements The authors would like to thank Ms. Y. H. Kim for the graphical work in this article.

\section{REFERENCES}

Alonso, C. D., M. H. R. B. Martins, J. Romano, and R. Godinho, 1997: SaoPaulo aerosol characterization study. J. Air Waste Management Assoc., 47, 1297-1300.

Chan, Y. C., R. W. Simpson, G. H. Mctainsh, P. D. Vowles, D. D. Cohen, and G. M. Bailey, 1999: Source apportionment of $\mathrm{PM}_{2.5}$ and $\mathrm{PM}_{10}$ aerosols in Brisbane (Australia) by receptor modeling. Atmos. Environ., 33, 3251-3268.

Chen, W. C., C. S. Wang, and C. C. Wei, 1997: An assessment of source contributions to ambient aerosols in Central Taiwan. J. Air Waste Management Assoc., 47, 501-509.

Chongju, 1996: Chongju statistical yearbook, Chongju city.

Chow, J. C., J. G. Watson, Z. Lu, D. H. Lowenthal, C. A. Frazier, P. A. Solomon, R. H. Thuillier, and K. Magliano, 1996: Descriptive analysis of $\mathrm{PM}_{2.5}$ and $\mathrm{PM}_{10}$ at regionally representative locations during SJVAQS/AUSPEX. Atmos. Environ., 30, 20792112.

Chung, Y. S., and M. B. Yoon, 1996: On the occurrence of yellow sand and atmospheric loadings. Atmos. Environ, 30, 2387-2397.

Gramotnev, G., and Z. Ristovski, 2004: Experimental investigation of ultra-fine particle size distribution near a busy road. Atmos. Environ., 38, 1767-1776.

Hazi, Y., M. S. A. Heikkinen, and B. S. Cohen, 2003: Size distribution of acidic sulfate ions in fine ambient particulate matter and assessment of source region effect. Atmos. Environ., 37, 5403-5413.

Huang, X., I. Olmez, and N. K. Aras, 1994: Emissions of trace elements from motor vehicles: potential marker elements and source composition profile. Atmos. Environ., 28, 13851391.

Kim, B. M., T. Solomon, and M. D. Zeidin, 2000: Characterization of $\mathrm{PM}_{2.5}$ and $\mathrm{PM}_{10}$ in the south coast air basin of southern California: part 1-spatial variations. J. Air Waste Management Assoc., 50, 2034-2044. 
Kim, K. H., G. H. Choi, C. H. Kang, J. H. Lee, J. Y. Kim, Y. H. Youn, and S. R. Lee, 2003: The chemical composition of fine and coarse particles in relation with the Asian Dust events. Atmos. Environ., 37, 753-765.

Lall, R., M. Kendall, K. Ito, and G. D. Thurston, 2004: Estimation of historical annual $\mathrm{PM}_{2.5}$ exposures for health effects assessment. Atmos. Environ., 38, 5217-5226.

Linda, Y. Z., and A. H. Martin, 1997: Size-resolved airborne particles and their morphology in central Jakarta. Atmos. Environ., 31, 1167-1172.

Lyons, J. M., C. Vrnkataraman, H. H. Main, and S. K. Friedlander, 1993: Size distributions of trace metals in the Los Angeles atmosphere. Atmos. Environ., 27, 237-249.

Mishra, V. K., K. H. Kim, C. H. Kang, and K. C. Choi, 2004: Wintertime sources and spatial distribution of airborne lead in Korea. Atmos. Environ., 38, 2653-2664.

Pakkanen, T. A., V. M. Kerminen, C. H. Korhonen, R. E. Hillamo, P. Aarnio, T. Koskentalo, and W. Maenhaut, 2001a: Use of atmospheric elemental size distributions in estimating aerosol sources in the Helsinki area. Atmos. Environ., 35, 5537-5551.

Pakkanen, T. A., K. Loukkola, C. H. Korhonen, M. Aurela, T. Makela, R. E. Hillamo, P. Aarnio, T. Koskentalo, A. Kousa, and W. Maenhaut, 2001b: Sources and chemical composition of atmospheric fine and coarse particles in the Helsinki area. Atmos. Environ., 35, 5381-5391.

Polisar, A. V., P. H. Hopke, and J. M. Harris, 2001: Source regions for atmospheric aerosol measured at Barrow, Alaska. Environ. Sci. Tech., 35, 4214-4226.

Seinfeld, J. H., 1986: Atmospheric Chemistry and Physics of Air Pollution, Wiley Interscience, New York, NY.

Spengler, J. D., and G. D. Thurston, 1983: Mass and elemental composition of fine and coarse particles in six U.S. cities. J. Air Waste Management Assoc., 33, 1162-1171.

Yao, X., A. P. S. Lau, M. Fang, C. K. Chan, and M. Hu, 2003: Size distributions and formation of ionic species in atmospheric particulate pollutants in Bejing, China: 1- inorganic ions. Atmos. Environ., 37, 2991-3000.

Zhuang, H., Chan, C. K., M. Fang, and A. S. Wexler, 1999. Size distributions of particulate sulfate, nitrate and ammonium at a coastal site in Hong Kong. Atmos. Environ., 33, 843-853. 